\title{
Study on Preparation and Properties of Tungsten Coating Based on WC Electrolysis
}

\author{
Qinghua Zhang ${ }^{1,2}$, Xiaoli Xi ${ }^{1,2, *}$, Wenxuan Qin $^{1}$, Liwen Zhang ${ }^{1}$, Liwen Ma ${ }^{2}$, Zuoren Nie ${ }^{1,2}$ \\ ${ }^{1}$ National Engineering Laboratory for Industrial Big-data Application Technology, Beijing University \\ of Technology, Beijing 100124, China \\ ${ }^{2}$ College of Materials Science and Engineering, Key Laboratory of Advanced Functional Materials, \\ Education Ministry of China, Beijing University of Technology, Beijing 100124, China \\ *E-mail: zhangqinghua@emails.bjut.edu.cn, xixiaoli@bjut.edu.cn
}

doi: $10.20964 / 2019.12 .11$

Received: 16 July 2019 / Accepted: 7 September 2019 / Published: 29 October 2019

Tungsten carbide (WC) is used as an anode in molten sodium tungstate to prepare a tungsten coating. Recovery of tungsten powder from WC electrolysis has been extensively studied, but the possibility of making available Tungsten coatings is still unrealized. A theoretical analysis was first carried out, and the feasibility of electrolysis was confirmed. Subsequently, this conclusion was also verified experimentally. In this experiment, the coating was studied by regulating the cathode current density. The tungsten coatings prepared at various current densities were characterized by X-ray Diffraction (XRD), Scanning Electron Microscope-Energy Dispersive Spectroscopy (SEM-EDS), nanoindentation tests, and Laser Scanning Confocal Microscopy LSCM. The results show that at a cathode current density of $70 \mathrm{~mA} \cdot \mathrm{cm}^{-2}$, an optimized tungsten coating can be obtained. The tungsten coating has a thickness of $4.1 \mu \mathrm{m}$ and a minimum average grain size.

Keywords: Molten salt, tungsten coating, tungsten carbide recovery

\section{$\underline{\text { FULL TEXT }}$}

(C) 2019 The Authors. Published by ESG (www.electrochemsci.org). This article is an open access article distributed under the terms and conditions of the Creative Commons Attribution license (http://creativecommons.org/licenses/by/4.0/). 